\title{
ANEMIA DE CÉLULAS FALCIFORMES
}

\author{
Walter Chaves MD*, Dolly Amador MD**, Jorge Sánchez MD***
}

\section{Resumen}

Presentamos dos mujeres que consultaron a urgencias por dolor abdominal agudo, iniciado pocas horas después de su llegada a Bogotá DC, asociado con síndrome anémico y hallazgos paraclínicos sugestivos de anemia de células falciformes, que se confirmó con electroforesis de proteínas en la consulta externa. La drepanocitosis, conocida como anemia de células falciformes, es una hemoglobinopatía estructural de causa genética que ocasiona clínica vasoclusiva con isquemia tisular secundaria generadora de crisis de dolor, que se exacerba entre otras razones por cambios de temperatura y de la presión del oxígeno atmosférico. Es importante causa de dolor agudo en pacientes de raza negra que asisten a urgencias al provenir con frecuencia de lugares cálidos.

Palabras clave: drepanocitosis, anemia de células falciformes, hemoglobinopatías, hemoglobina $\mathrm{S}$.

\section{SICKLE-CELL ANEMIA}

\section{Abstract}

We report the cases of two women who consulted to the emergency department due to abdominal pain that started a few hours after arriving to Bogotá DC, associated with anemic syndrome and laboratory tests findings suggestive of sickle-cell anemia confirmed by protein electrophoresis in the outpatient clinic. Drepanocytosis, or sickle-cell anemia, is an inherited structural hemoglobin disorder manifested by vaso-occlusive crises followed by secondary ischemic tissue injury generating pain crises, which exacerbate, among other reasons, due to changes in temperature and of atmospheric oxygen pressure. It is an important cause of acute pain in the black population who visit the emergency room when arriving most commonly from places at low altitude.

Key words: drepanocytosis, sickle-cell anemia, hemoglobinopathies, hemoglobin $\mathrm{S}$.

Fecha recibido: enero 31 de 2014 - Fecha aceptado: junio 26 de 2014

* Instructor Asociado. Fundación Universitaria de Ciencias de la Salud. Jefe del Servicio de Medicina Interna, Hospital de San José. Bogotá DC, Colombia.
** Residente I de Medicina Interna, Fundación Universitaria de Ciencias de la Salud. Bogotá DC. Colombia.

*** Residente III de Medicina Interna, Fundación Universitaria de Ciencias de la Salud. Bogotá DC, Colombia. 


\section{Introducción}

La anemia de células falciformes es la hemoglobinopatía estructural más frecuente en nuestro medio ${ }^{1}$, sus manifestaciones clínicas son un espectro amplio que incluye fenómenos vasoclusivos en diferentes órganos, ocasionando crisis dolorosas paroxísticas, microinfartos y sus consecuencias. En Colombia la prevalencia no está bien establecida, es mayor en algunos territorios del país, en especial donde predomina la población negra encontrándose hasta $10 \%$ de rasgo falciforme en alguno de esos territorios. Teniendo en cuenta la variedad de manifestaciones clínicas, los pacientes son sometidos a múltiples pruebas diagnósticas. Consideramos que una valoración integral por parte del clínico orienta el diagnóstico y manejo temprano de esta entidad. A continuación se presentan dos pacientes de sexo femenino que ingresaron al servicio de urgencias del Hospital de San José de Bogotá DC en septiembre 2013, consultando por dolor sin comorbilidad previa y con el antecedente de ser visitantes, ambas provenientes de regiones cálidas del país. Se comenta el proceso diagnóstico, tratamiento intrahospitalario y conducta al egreso.

Reporte del primer caso: mujer de 23 años de edad, natural y procedente de Valledupar, Cesar, estudiante universitaria, que consultó al servicio de urgencias por cefalea pulsátil generalizada de intensidad 9/10 no irradiada, catalogada como "la peor de su vida", asociada con fosfenos, náuseas, astenia, adinamia y eventos eméticos de contenido alimentario. Niega antecedentes patológicos previos. Presión arterial de 91/45 mm $\mathrm{Hg}$, frecuencia cardiaca 124 por minuto y respiratoria veinte. Palidez mucocutanea generalizada, escleras con leve tinte ictérico, ruidos cardíacos con soplo pansistólico en todos los focos, sin déficit neurológico, el resto del examen físico era normal. Los laboratorios mostraron leucocitos $24.500 / \mathrm{mm}^{3}$, neutrófilos $16.600 /$ $\mathrm{mm}^{3}$, linfocitos $5.800 / \mathrm{mm}^{3}$, monocitos $2.100 / \mathrm{mm}^{3}$, hemoglobina $5,5 \mathrm{~g} / \mathrm{dL}$, hematocrito $15,9 \%$, volumen corpuscular medio 95,5, hemoglobina corpuscular media $34,6 \mathrm{pg} / \mathrm{dL}$, plaquetas $235.000 / \mathrm{mm}^{3}$ y reticulocitos 18\%. A la ecografía abdominal hay esplenomegalia, el TAC cerebral simple reveló imagen hipodensa en la sustancia blanca periventricular adyacente al asta frontal del ventrículo lateral izquierdo. En la resonancia magnética cerebral se ve área hiperintensa en T2 y flair compatible con isquemia aguda en región frontal izquierda. El angiotac fue negativo para tromboembolismo pulmonar, presentó derrame pleural bilateral de aspecto libre de predominio derecho y atelectasias basales del mismo lado.

Por el lugar de procedencia, el cuadro clínico y la presencia de drepanocitos en el frotis de sangre periférica, se pensó en crisis vasoclusivas secundarias a anemia de células falciformes. Se inició manejo con hidroxiúrea, hidratación vigorosa, morfina y heparina de bajo peso molecular en rango de tromboprofilaxis, con lo cual hubo importante mejoría clínica, sin deterioro hemodinámico. Ante la sospecha de anemia de células falciformes se tomaron muestras para electroforesis de hemoglobina que revelaron $\mathrm{Hb} \mathrm{A} 28,8 \%, \mathrm{Hb} \mathrm{A} 2$ $3,1 \%$, $\mathrm{Hb} \mathrm{C}$ ausente, $\mathrm{Hb}$ fetal 3,1 y $\mathrm{Hb} \mathrm{S} 65 \%$, confirmando el diagnóstico de drepanocitosis.

Reporte del segundo caso: mujer de 64 años de edad natural de Tumaco procedente de Ibagué (hacía cinco días), con antecedentes de hipotiroidismo en manejo con levotiroxina 100 microgramos día, fibromialgias y esclerodermia, remitida de otra institución para estudio de dolor abdominal desde hacía cinco días, de inicio súbito, intermitente, punzante, de predominio en hipocondrio izquierdo, con intensidad 7/10 asociado con polimialgias y malestar general. Presión arterial de 100/65 mm Hg, frecuencia cardíaca 78 por minuto y respiratoria 16. Presentaba palidez mucocutanea generalizada, hepatoesplenomegalia dolorosa a la palpación y abdomen sin signos de irritación peritoneal. El perfil inmunológico fue negativo, leucocitos $12.900 \mathrm{~mm}^{3}$, neutrófilos $5.600 \mathrm{~mm}^{3}$, linfocitos $5.700 \mathrm{~mm}^{3}$, monocitos $1.300 \mathrm{~mm}^{3}$, hemoglobina $11 \mathrm{~g} / \mathrm{dL}$ hematocrito $34.1 \%$, volumen corpuscular medio 71,5 , hemoglobina corpuscular media 32.2 y plaquetas $309.000 \mathrm{~mm}^{3}$. El extendido de sangre periférica mostró glóbulos rojos microciticos hipocrómicos, policromatofilia, eritrocitos nucleados y drepanocitos. Recuento de retículocitos $4.65 \%$, tiempo de protrombina $10,8 \mathrm{seg}$. $(10,7 \mathrm{seg})$, tiempo parcial de tromboplastina 31,1 segundos, nitrógeno ureico $14 \mathrm{mg} / \mathrm{dL}$, creatinina $0,7 \mathrm{mg} / \mathrm{dL}$, sodio 150 , potasio $4,5 \mathrm{mmol} / \mathrm{L}$, cloro $115 \mathrm{mmol} / \mathrm{L}$, calcio 
8,9 mg/dL y albumina 3,5 g/dL, LDH 665 u/L, ASAT/ TGO 17, TGP ALAT $35 \mathrm{U} / \mathrm{L}$, bilirrubina total $0,7 \mathrm{mg} /$ $\mathrm{dL}$, conjugada $0,3 \mathrm{mg} / \mathrm{dL}$ no conjugada $0,4 \mathrm{mg} / \mathrm{dL}$ y TSH $0,25 \mathrm{Ul} / \mathrm{ml}$. Un TAC abdominal extrainstitucional reveló evidencia de imágenes focales interpretadas como posibles infartos esplénicos.

La paciente presenta una evolución clínica con tendencia a la mejoría tras el inicio de hidroxiúrea y optimización de líquidos endovenosos con hemograma sin cambios, por lo que se decidió egreso hospitalario previa toma de muestra para electroforesis de hemoglobinas con lectura ambulatoria, reportadas como $\mathrm{HbA}$ 19,4\%, HbA2 6,6\%, HbC ausente, $\mathrm{HbS} 67,8 \%$ y $\mathrm{Hb}$ fetal 6,2 confirmando el diagnóstico de drepanocitosis.

\section{Discusión}

La anemia de células falciformes se caracteriza por un espectro variable de manifestaciones clínicas, en este caso dos mujeres que consultan por dolor como síntoma cardinal tras el arribo a nuestra ciudad, provenientes de áreas del país localizadas a bajas alturas y temperaturas cálidas.

Es una enfermedad genética, autosómica dominan$t^{1}$, conocida como la hemoglobinopatía estructural más frecuente en nuestro medio ${ }^{2}$, ocasionada por una mutación puntual consistente en la sustitución del aminoácido valina (polar) por ácido glutámico (hidrófobo, no polar) en la posición 6 de la cadena beta de hemoglobina sintetizada en el brazo corto del cromosoma $11 .^{2}$ La hemoglobina $\mathrm{S}$ es la que inicia la explicación de los fenómenos de vasoclusión, pues sus moléculas se polimerizan ante la desoxigenación aumentando la viscosidad del glóbulo rojo, produciendo cambios en la membrana y deformando la célula. Estos tienen mayor dificultad para pasar los pequeños capilares, por lo que son destruidos en forma prematura (hemólisis), produciendo además, oclusión de los vasos sanguíneos (vasooclusión). La sobrevida de los glóbulos rojos con Hb SS es de 10 a 15 días, comparada con los 120 días cuando la hemoglobina es normal. El aumento en la hemoglobina fetal $(\mathrm{Hb} \mathrm{F})$ disminuye la polimerización de la $\mathrm{Hb} \mathrm{S}$, debido a la afinidad de la $\mathrm{Hb} \mathrm{F}$ por el oxígeno, lo que reduce la posibilidad de polimerización.
Se puede ser homocigoto para la enfermedad lo que quiere decir que los dos genes son anormales y solo se sintetiza HB S (90 a 100\%) o heterocigoto cuando un gen es normal y el otro anormal, y la concentración de $\mathrm{Hb} \mathrm{S}$ en el glóbulo rojo varía entre el 20 y 40\%. ${ }^{3}$ En ambientes de hipoxia (alturas), acidosis, bajas temperaturas o bajas corrientes iónicas, ocurre un proceso de polimerización no covalente de la hemoglobina lo que genera el conocido fenómeno de falciformación, modificación progresiva en la morfología de los hematíes, volviéndolos rígidos, ocasionando fenómenos de vasoclusión, que incluso puede llevar a la muerte. ${ }^{4}$ Ser portador del gen es muy diferente a padecer la enfermedad, un paciente homocigoto presenta la enfermedad desde etapas muy tempranas, afectando la calidad de vida con pronóstico reservado a corto plazo. ${ }^{4}$ Las manifestaciones clínicas en heterocigotos son menores y más tardías, con una tasa menor de morbimortalidad por complicaciones de la enfermedad, predominando los procesos infecciosos secundarios a la asplenia funcional que estos pacientes presentan. ${ }^{5}$

El nexo epidemiológico es sin lugar a dudas el factor más importante a la hora del diagnóstico. Se sabe que la mayor incidencia de drepanocitosis se encuentra en la población negra de África Ecuatorial, donde se reconoce la mutación en el $40 \%$ de la población. ${ }^{6}$ Ser portador del gen (heredar una sola copia) representa protección frente al paludismo, hecho conocido desde hace más de 60 años en la descripción de Haldane de 1949. Desde entonces diferentes estudios lo confirmaron y eso explica la persistencia de polimorfismo genético en nuestra población. ${ }^{7}$ Debido al proceso migratorio de estas poblaciones a partir del siglo XV hacia América, se sabe que al menos en Estados Unidos cerca de uno de cada doce afroamericanos poseen el rasgo falciforme y al menos uno de cada 36.000 hispanos.

En Colombia la prevalencia de la enfermedad no está bien establecida, pero en algunas zonas del país se habla hasta de $10 \% .{ }^{8}$ Conocer los aspectos epidemiológicos aumenta la probabilidad del diagnóstico. Ante la exposición a un ambiente de hipoxia tisular se generan crisis vasooclusivas que llevan a infartos esplénicos y autoesplenismo, los cuales representan una de las manifestaciones más típicas en pacientes heterocigotos. ${ }^{5}$ 
Son distintos los mecanismos que llevan al proceso de oclusión vascular, se requieren condiciones predisponentes para la ocurrencia de una crisis, un tiempo específico de exposición a factores desencadenantes, la estasis sanguínea, una concentración especifica de iones en sangre, predisposición a la adhesión endotelial y por supuesto la $\mathrm{Hb} \mathrm{S}$ en el interior de los glóbulos rojos. Muchas veces las crisis de oclusión pueden ser tan severas que ocasionan isquemia o incluso necrosis en el área distal a la oclusión, lo cual genera estímulos dolorosos y se convierte en la causa del cuadro abdominal agudo. La mayor complicación es el choque hipovolémico. ${ }^{9}$

Una de las principales causas de muerte en pacientes con la enfermedad de células falciformes corresponde a accidentes cerebrovasculares, con una tasa hasta de $0,76 \%$ en menores de 20 años, al menos 300 veces mayor que en pacientes sin anemia de células falciformes. ${ }^{4} \mathrm{Si}$ bien es cierto que dentro de la definición de ACV no siempre se incluyen los infartos silentes y depende de la publicación que se revise, cualquier evento neurológico agudo secundario a una oclusión o hemorragia que resulta en un evento isquémico asociado con síntomas neurológicos, corresponde a un cuadro de ACV. ${ }^{10}$

Las complicaciones pulmonares representan la mayor causa de muerte y de hospitalizaciones. ${ }^{11}$ El principal diagnóstico a tener en cuenta en un paciente con antecedente de anemia de células falciformes y dolor torácico, debe corresponder al síndrome torácico agudo, pues requiere UCI con soporte ventilatorio, inotrópico, vasoactivo y muerte en el $25 \%$ de los casos. ${ }^{4}$ El síndrome torácico agudo se define como un nuevo cambio o hallazgo en la radiografía de tórax acompañado de fiebre o síntomas respiratorios, que una vez sospechado exige tratamiento inmediato para prevenir el deterioro clínico y la muerte. ${ }^{12} \mathrm{El}$ manejo sintomático en la mayoría de los casos como la hidratación endovenosa optima, oxígeno e hidroxiúrea, suelen ser la solución. ${ }^{13}$ No obstante es importante antes de iniciar el tratamiento considerar los diagnósticos diferenciales, como embolismo pulmonar, infecciones, síndrome coronario agudo y enfermedad crónica pulmonar. ${ }^{14,15}$
El tratamiento es multidisciplinario, comenzando con la educación del paciente acerca de la condición genética de su enfermedad, de la prevención de las complicaciones y por supuesto del manejo de las mismas. ${ }^{16} \mathrm{La}$ vacunación frente a organismos capsulados es la piedra angular de la prevención de infecciones (Streptococcus pneumoniae, Neisseria meningitidis, Haemophilus influenzae tipo B y virus de la hepatitis B).

La terapia más empleada incluye el manejo con líquidos endovenosos y oxígeno. La hidroxiúrea es el medicamento más estudiado demostrando disminución en las tasas de mortalidad y de hospitalizaciones, e incremento de la supervivencia. ${ }^{17} \mathrm{Si}$ bien su mecanismo de acción aún no está bien establecido ${ }^{18}$, se incluyen su capacidad para inhibir la síntesis de $\mathrm{ADN}$ en la fase $\mathrm{S}$ del ciclo celular, la activación del gen de hemoglobina fetal llevando a disminución en la polimerización de la $\mathrm{Hb} \mathrm{S}$ y aumento de la sobreviva del glóbulo rojo con disminución de las crisis vasoclusivas. Se ha encontrado relación con la disminución en la expresión de los neutrófilos y por lo tanto de la liberación de factores quimiotácticos y de los mecanismos proinflamatorios que conlleva su expresión, menor interacción entre la célula endotelial y los glóbulos rojos, mejorando la hidratación de los mismos y por lo tanto su deformabilidad. ${ }^{19}$ En el $40 \%$ de los pacientes que no responden o presentan falla orgánica progresiva con la hidroxiúrea, se deben utilizar otras opciones terapeúticas. Alternativas a la hidroxiúrea son el trasplante de médula ósea y la terapia de transfusión, que disminuyen la morbimortalidad y representan la primera línea en un grupo limitado de personas incluidos los pacientes que no responden al manejo óptimo con hidroxiúrea. ${ }^{20}$ El único tratamiento curativo de la anemia de células falciformes hoy en día es el trasplante alogénico de médula ósea de donante familiar histocompatible. Los resultados en las series publicados tanto en Europa como en Estados Unidos muestran que el $85 \%$ sobreviven curados de su enfermedad. Cerca del $10 \%$ fallecen de complicaciones y $5 \%$ presentan un fracaso de implante y reconstitución autóloga. ${ }^{21}$

Las indicaciones actuales para el trasplante de medula ósea son bastante claras y específicas, incluyen el haber presentado complicaciones importantes frecuentes, 
eventos cerebrovasculares y además contar con un hermano donante sano. Menos de $30 \%$ de las personas con enfermedad de células falciformes tienen donantes hermanos compatibles lo que restringe esta opción curativa a pocos pacientes, por lo que el uso de donantes alternativos es un área activa de investigación. ${ }^{22,23}$

\section{Referencias}

1. Rees DC, Williams TN, Gladwin MT. Sickle-cell disease. Lancet. 2010;376(9757):2018-31.

2. Bender MA, Hobbs W. Sickle cell disease. In: Pagon RA, Adam MP, Ardinger HH, Bird TD, Dolan CR, Fong CT, et al. GeneReviews ${ }^{\mathrm{TM}}$ [monografía en Internet]. Washington, Seattle; 1993-2014 [citado 9 Jul 2014]. Disponible en: http:// www.ncbi.nlm.nih.gov/books/NBK1377/

3. Denis M. Sickle cell anemia. In: Miller LP, editor. Blood diseases of infancy and childhood. 7th ed. St. Louis, Toronto: Mosby; 1995. p. 415.

4. Platt OS, Brambilla DJ, Rosse WF, Milner PF, Castro O, Steinberg MH, et al. Mortality in sickle cell disease. Life expectancy and risk factors for early death. N Engl J Med. 1994;330(23):1639-44.

5. Lane PA, O'Connell JL, Lear JL, Rogers ZR, Woods GM, Hassell KL, et al. Functional asplenia in hemoglobin SC disease. Blood. 1995;85(8):2238-44.

6. Tsaras G, Owusu-Ansah A, Boateng FO, Amoateng-Adjepong Y. Complications associated with sickle cell trait: a brief narrative review. Am J Med. 2009;122(6):507-12

7. Gong L, Parikh S, Rosenthal PJ, Greenhouse B. Biochemical and immunological mechanisms by which sickle cell trait protects against malaria. Malar J. 2013;12(1):317.

8. Durán CL, Morales OL, Echeverri SJ, Isaza M. Haplotipos del gen de la globina beta en portadores de hemoglobina $\mathrm{S}$ en Colombia. Biomedica. 2012;32(1):103-11.

9. Solanki DL, Kletter GG, Castro O. Acute splenic sequestration crises in adults with sickle cell disease. Am J Med. 1986;80(5):985-90.

10. Powars D, Wilson B, Imbus C, Pegelow C, Allen J. The natural history of stroke in sickle cell disease. Am J Med. 1978;65(3):461-71.
11. Minter KR, Gladwin MT. Pulmonary complications of sickle cell anemia. A need for increased recognition, treatment, and research. Am J Respir Crit Care Med. 2001;164(11):2016-9.

12. Ballas SK, Lieff S, Benjamin LJ, Dampier CD, Heeney MM, Hoppe C, et al. Definitions of the phenotypic manifestations of sickle cell disease. Am J Hematol. 2010;85(1):6-13.

13. Nagalla S, Ballas SK. Drugs for preventing red blood cell dehydration in people with sickle cell disease. Cochrane Database Syst Rev. 2012;7:CD003426.

14. Vichinsky E, Williams R, Das M, Earles AN, Lewis N, Adler A, et al. Pulmonary fat embolism: a distinct cause of severe acute chest syndrome in sickle cell anemia. Blood. 1994;83(11):3107-12.

15. Vichinsky EP, Neumayr LD, Earles AN, Williams R, Lennette ET, Dean $\mathrm{D}$, et al. Causes and outcomes of the acute chest syndrome in sickle cel disease. National Acute Chest Syndrome Study Group. N Engl J Med. 2000;342(25):1855-65.

16. National Institute of Health, National Heart Lung and Blood Institute. The management of sickle cell disease [monografía en Internet]. Washington: The Institute; 2004 [citado 9 Jul 2014]. Disponible en: http://www.nhlbi.nih.gov/health/prof/ blood/sickle/sc_mngt.pdf

17. Davies S, Olujohungbe A. Hydroxyurea for sickle cell disease. Cochrane Database Syst Rev. 2001(2):CD002202.

18. Segal JB, Strouse JJ, Beach MC, et al. Hydroxyurea for the treatment of sickle cell disease [monografía en Internet]. Rockville (MD): Agency for Healthcare Research and Quality; 2008 [citado 9 Jul 2014]. Disponible en: http://www.ncbi. nlm.nih.gov/books/NBK38503/

19. Halsey C, Roberts IA. The role of hydroxyurea in sickle cell disease. Br J Haematol. 2003;120(2):177-86.

20. Platt OS. Hydroxyurea for the treatment of sickle cell anemia. N Engl J Med. 2008;358(13):1362-9.

21. Ortega Aramburu JJ. [Sickle-cell anemia: an emerging disease in Spain]. An Pediatr (Barc). 2003;58(2):93-4

22. Wilson RE, Krishnamurti L, Kamat D. Management of sickle cell disease in primary care. Clin Pediatr (Phila). 2003;42(9):753-61.

23. Ruggeri A, Eapen M, Scaravadou A, Cairo MS, Bhatia M, Kurtzberg J, et al Umbilical cord blood transplantation for children with thalassemia and sickle cell disease. Biol Blood Marrow Transplant. 2011;17(9):1375-82. 